\title{
Cuerpo extraño en Retzius con absceso paravesical
}

\author{
Unusual foreign body in Retzius with paravesical abscess
}

María Tudela L. ${ }^{1}$, Jaime Zorrilla O. ${ }^{1}$, Enrique Ramón B. ${ }^{1}$ y Emilio Del Valle H. ${ }^{1}$

Varón de 59 años con antecedente de laminectomía L5-S1 que consulta dos meses después de la cirugía por molestias glúteas y síntomas del tracto urinario inferior sin supuración perianal y sin fiebre. A la exploración empastamiento glúteo derecho. Se realizó Resonancia Magnética que mostraba una colección en el espacio isquiorrectal derecho que se extendía hasta el Retzius y en su interior existía un cuerpo extraño (Figuras 1,2 y 3). El paciente se intervino de urgencias, a través de una laparotomía media infraumbilical, hallándose un palillo de dientes de madera paravesical derecho (Figura 4).

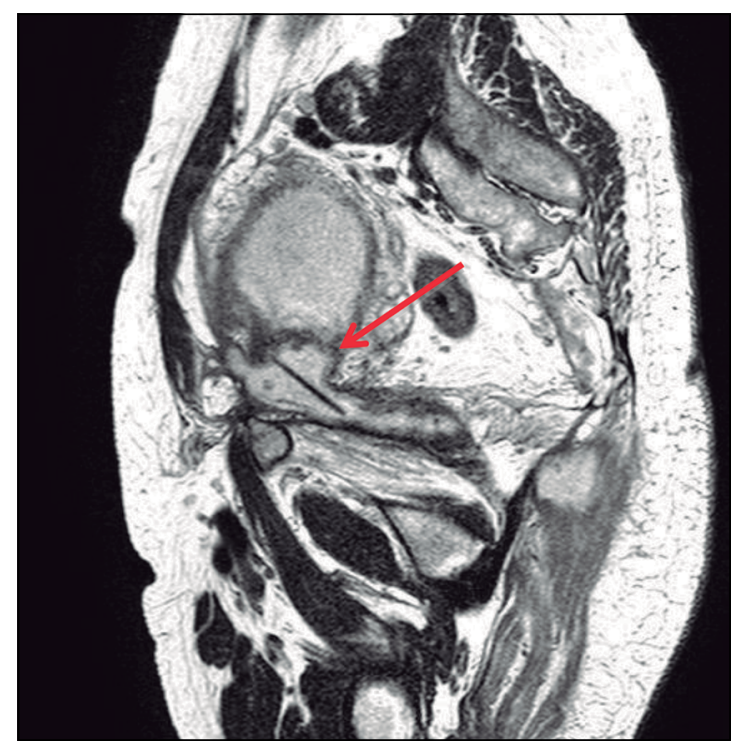

Figura 2. Secuencia turbo espin eco potenciada en T2. Corte sagital oblicuo en la pelvis. Cuerpo extraño en el interior de la colección (flecha).

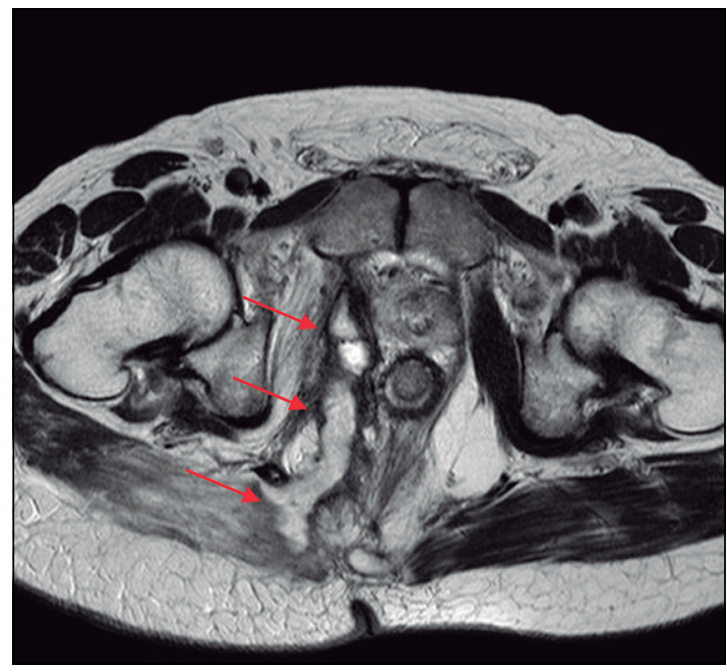

${ }^{1}$ Hospital Universitario Gregorio Marañón.

Conflicto de Intereses: Los autores declaran que no existe conflicto de intereses.

Sin financiamiento.

Recibido el 9 de febrero de 2018, aceptado para publicación el 9 de abril de 2018

\section{Correspondencia a:} María Tudela Lerma Cirugía General y Digestivo. Hospital Universitario Gregorio Marañón.

Duque de Sesto $175^{\circ} \mathrm{C}$ CP28009 Madrid España. matuler@hotmail.com

Figura 1. Secuencia turbo espin eco potenciada en T2. Corte axial en la pelvis. Colección en el espacio isquiorrectal derecho (flechas).

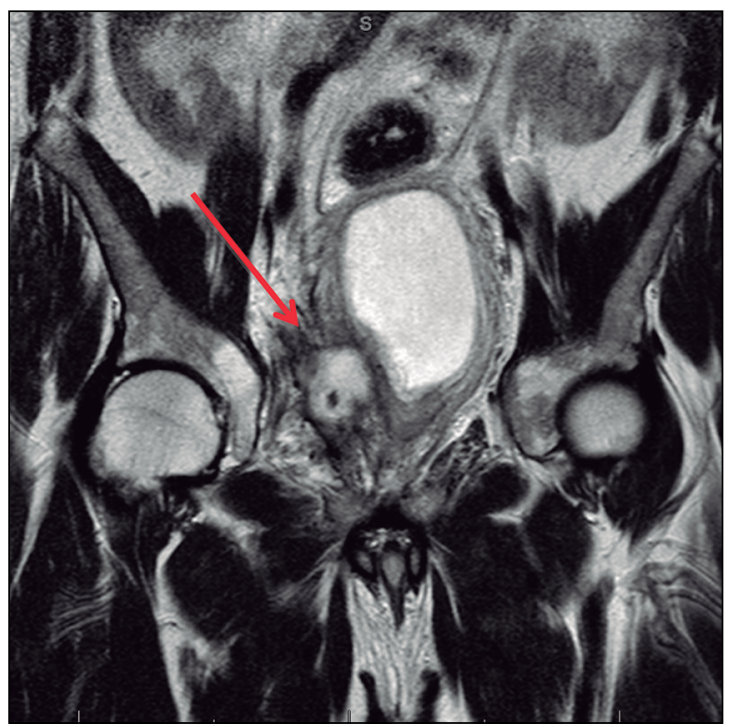

Figura 3. Secuencia turbo espin eco potenciada en T2. Corte coronal en la pelvis. Espacio paravesical derecho. 


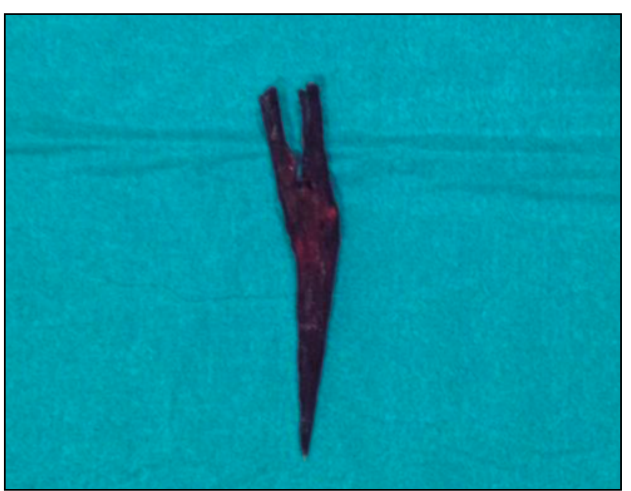

Figura 4. Cuerpo extraño.

\section{Responsabilidades éticas}

Protección de personas y animales. Los autores declaran que para esta investigación no se han realizado experimentos en seres humanos ni en animales.

Confidencialidad de los datos. Los autores declaran que han seguido los protocolos de su centro de trabajo sobre la publicación de datos de pacientes.

Conflictos de interés: no hay.

\section{Referencias}

1. Goh BK, Chow PK, Quah HM, Ong HS, $\mathrm{Eu} \mathrm{KW}$, Ooi LL, et al. Perforation of the gastrointestinal tract secondary to ingestion of foreign bodies. World J Surg. 2006;30:372-7.

2. Leelouche N, Ayoub N, Bruneel F, Mignon F, Troche G, Boisrenault $\mathrm{P}$, et al. Thigh cellulitis caused by toothpick ingestion. Intensive Care Med. 2003;29:662-3.

3. Bennetsen DT. Perirectal abscess after accidental toothpick ingestion. J Emerg Med. 2008;34:203-4.

4. Byrne CM, Lim JK, Stewart PJ. Ischiorectal abscess caused by ingested bones. ANZ J Surg. 2004;74:818-9.

5. Ooi BS, Ho YH, Eu KW, Nyam D, Leong A, Seow-Choen F. Management of anorectal foreign bodies: a cause of obscure anal pain. Aust N Z J Surg. 1998;68:852-5.

6. Su YJ, Lai YC, Chen CC, Tang C. Intraabdominal abscess caused by toothpick injury. Int J Infect Dis. 2009;13:e264-6.

7. Chen CK, Su YJ, Lai YC, Cheng HK, Chang WH. Fish bone-related intraabdominal abscess in an elderly patient. Int J Infect Dis. 2010;14:e171-2. 